\title{
Artikkeli
}

\section{Kolmas tila suhteisuuden näyttämönä - mediaviitteet ja läheisten nimet yhteisöllisyyden osoittajina esiopetusikäisten lasten luovassa kirjoittamisessa}

\begin{abstract}
Pienten lasten luovaa kirjoittamista on tutkittu vähän ja yleensä vain teknistä tarkkuutta korostavan taitodiskurssin kautta. Kirjoittaminen voidaan kuitenkin ymmärtää myös tarkoitushakuisena sosiaalisena toimintana, jaettavaan muotoon taltioituina ideoina, näkemyksinä ja mielipiteinä - suhteina. Työssäni suhteisuuden teoreettisen viitekehyksen muodostaa kolmannen tilan käsite, jolla tarkoitan ei-institutionaalisen sekä institutionaalisen kasvuympäristön rajapinnoille muodostuvia molemmat kontekstit sisältäviä identiteettiperustaisia tiloja. Empiirinen aineisto koostuu esiopetusikäisten lasten päiväkotikontekstissa vapaan leikin aikana tuottamista (tietokone)kirjoituksista. Tarkastelen erityisesti sitä millaisia, keiden välisiä ja miten ilmaistuja suhteita lapset julkituovat kirjoituksissaan kolmannen tilan kautta. Kolmas tila esiintyi kirjoituksissa joko oman lähipiirin tai mediatekstien uudelleenkontekstualisointina. Valinnat eivät olleet sattumanvaraisia vaan kertoivat kiintymyksestä ja jo olemassa olevista tai toivotuista ystävyyssuhteista. Kirjoituksissa esiintyneiden lasten välittömään kokemusmaailmaan kuuluvien henkilöiden roolit ja relaatiot elivät kirjoituksissa omalakista elämäänsä, jossa esimerkiksi vanhempien ja lasten roolit usein sekoittuivat. Mediaviitteiden intersubjektiivinen suhteisuus ilmeni tarkoituksenmukaisena ja koordinoituna saman jaetun keskusteeman ympärillä pysyttelemisenä.
\end{abstract}

AVAINSANAT: kolmas tila, suhteisuus, mediakulttuuri, varhaiskasvatus ja kirjoittaminen

A Ile kouluikäisten lasten luova kirjoittaminen on vähän tutkittu ilmiö ja kirjoituksia on analysoitu pääosin teknistä tarkkuutta korostavan taitodiskurssin näkökulmasta (Ivanic 2004; Suvilehto 2008, 13). Myös kirjoittamisen ja mediakulttuurin väliset suhteet varhaiskasvatuksen kontekstissa ovat Suomessa vielä tutkimatonta maaperää. Yksi syy tähän lienee se, ettei kirjoittamista mielletä alle kouluikäisille lapsille ominaiseksi itseilmaisun muodoksi. Syksyllä 2016 käyttöönotettavissa uusissa esi- ja perus- 
opetuksen opetussuunnitelmien perusteissa luku- ja kirjoitustaidon käsite kuitenkin laajenee monilukutaidoksi (multiliteracy), jolla tarkoitetaan erilaisten viestien tulkinnan ja tuottamisen taitoja. Nämä viestit voivat olla esimerkiksi sanallisia, kuvallisia, numeerisia tai näiden yhdistelmiä. Perusteiden mukaan myös opetuksen metodeissa ja sisällöissä lasten monimuotoinen mediakulttuuri tulee ottaa huomioon. (Opetushallitus 2014a, 11-12; 2014b, 20-21, 28.) Nykypäivän lasten saatavilla onkin valtava määrä erilaisia mediatekstejä (Suoninen 2014, 63), joista lapset siirtävät elementtejä leikkeihin, piirroksiin ja keskusteluihin peilaten näin mediakulttuurisia kokemuksiaan sekä omaa elämäänsä. Osaltaan mediakulttuurin tarjoamat kokemukset myös tuottavat tarvetta ja halukkuutta omaan ilmaisuun (Hesterman 2011; Niinistö \& Ruhala 2007, 124; Niinistö \& Sintonen 2007, 27).

Vaikka media ymmärretään päiväkodeissa merkittäväksi kasvu- ja oppimisympäristöksi, kokevat varhaiskasvattajat ydintehtäväkseen lasten suojelemisen median haitallisilta vaikutteilta (Mediakasvatus... 2013; Suoninen 2008; ks. Kellner \& Share 2005). Suojelutehtävällä on toki paikkansa, mutta varhaisvuosien mediakasvatus ei voi rajoittua vain siihen, vaan mediakulttuuri on tunnistettava myös pedagogiseksi resurssiksi. Lapsille tärkeät mediahahmot voivat toimia esimerkiksi viitekehyksenä, jonka kautta lasten on mahdollista harjoitella erilaisten perinteisten ja modernien tekstityyppien ymmärtämistä, tuottamista ja yhdistämistä (ks. Hesterman 2011; Vera 2011). Koska medialukutaito sijoittuu osaksi monilukutaitoa (Opetushallitus 2014a, 11), tulee populaarimedia lisäksi ymmärtää itsessään arvokkaaksi tekstilajiksi, ei pelkäksi motivointivälineeksi (vrt. Marsh 2006).

Työssäni tarkastelen suhteisuuden näkökulmasta kuusi- ja seitsemänvuotiaiden lasten esiopetuskontekstissa vapaan leikin aikana tuottamien (tietokone)kirjoitusten sisältöjä. Suhteisuuden teoreettisen viitekehyksen muodostaa kolmannen tilan käsite (ks. Wilson 2000), jolla tarkoitetaan kahden eri kontekstin rajapinnoille muodostuvaa molemmat kontekstit sisältävää tilaa. Tässä tutkimuksessa kontekstit ovat institutionaalinen kasvu- ja oppimisympäristö sekä ei-institutionaalinen kasvu ja oppimisympäristö (ks. Kupiainen 2007b; Pahl \& Rowsell 2005), eli päiväkodissa toimiva esiopetusryhmä sekä sen ulkopuoliset fyysiset, sosiaaliset ja kulttuuriset ympäristöt. Artikkelissani analysoin kasvatusviitekehyksen sisältäviä tulkintoja kolmannesta tilasta ja esitän siitä sen alkuperäistä kriittistä luonnetta mukailevan tulkintani, jossa lähestyn kolmatta tilaa identiteettiperustaisena kokemuksellisena tilana. Lisäksi tarkennan kolmannen tilan käsitettä liittämällä siihen mikrokontekstit ja niiden väliset suhteet. Tämän tutkimuksen viitekehyksessä suhteisuus voidaankin ymmärtää esimerkiksi kirjoittajan suhteena mediaviitteen lähteeseen (esim. affektio), kasvatuskontekstin työntekijöiden suhteena mediaviitteen lähteeseen (esim. suojeludiskurssi) sekä mediaviitteiden suhteena lasten intersubjektiiviseen suhteisuuteen (esim. teemojen tarkoituksenmukainen koordinointi). Mediaviitteiden lisäksi käsittelen suoraan ilmaistua suhteisuutta eli kirjoituksia, joissa lapset ovat nimenneet ystäviään tai perheenjäseniään, sekä koalitiokirjoituksia, eli kahden tai useamman lapsen yhteistuotoksia. Artikkelin aluksi käyn läpi kolmannen tilan käsitettä ensin yleisemmällä tasolla. Sen jälkeen tarkastelen esiopetuskontekstia, mediakulttuuria ja kirjoittamista. 


\section{Kolmas tila ja institutionaalinen (varhais)kasvatus}

Kolmannen tilan käsite juontaa juurensa Homi K. Bhabhan (1994) näkemyksiin maahanmuuttajien hybridimäisestä tilasta uuden ja vanhan kulttuurin välissä, integraation ja segregaation ristipaineessa. Laajimmillaan kolmas tila kuvastaa sitä, että eri tavoin rakentuneet tiedolliset ja diskursiiviset varannot voivat sosiaalisesta ja kulttuurisesta kontekstista riippuen olla joko itseilmaisun mahdollistajia tai rajoittajia. Sellaisina ne ovat myös merkityksellisiä yksilön identiteetin muodostumiselle. (Esim. Levy 2008; Moje 2004; Wilson 2000.) Kuten Stuart Hall $(2005,71)$ toteaa, muodostaa yksilö identiteettinsä mahdollisuuksien ja rajoitteiden limittymänä.

Kirjoittamiseen kolmannen tilan käsitteen on ensimmäisenä liittänyt vankien kirjoittamista tutkinut Anita Wilson (2000). Myöhemmin kolmatta tilaa on myös hahmoteltu lukutaitojen näkökulmasta koulu- ja kotikontekstien välisenä alueena (Levy 2008; Pahl \& Rowsell 2005). Kotimaiseen tutkimukseen käsitteen on lanseerannut Reijo Kupiainen (2007b). Sekä Pahl ja Rowsell $(2005,66)$ että Kupiainen (2007b; ks. Niinistö \& Ruhala 2007, 124) ovat myös visualisoineet koulu- ja ei-koulukonteksteja yhdistävän kolmannen tilan (kuvio 1 ja kuvio 2).

Kuvio 1. Kolmas tila (Pahl \& Rowsell 2005, 66)

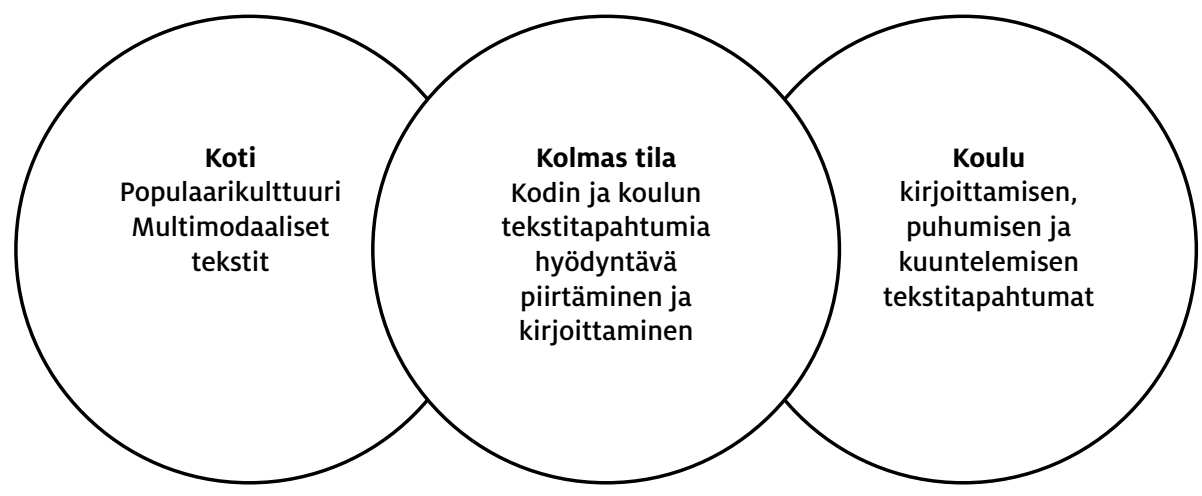

Kuvio 2. Kolmas tila (Kupiainen 2007b; Niinistö \& Ruhala 2007, 124)

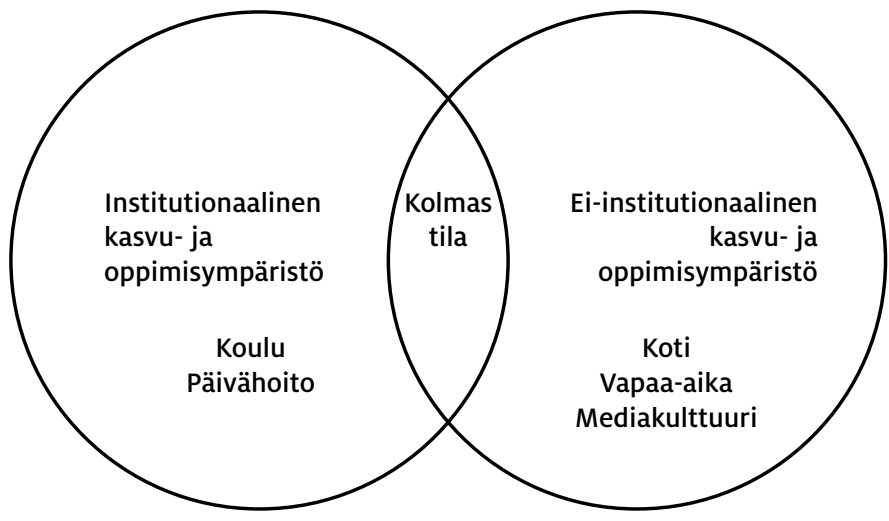


Kupiaisen (2007b) visualisointi ja siinä käytetyt sanavalinnat tavoittavat Pahlin ja Rowsellin $(2005,66)$ mallinnusta paremmin ympäristöjen moninaisuuden. Pahlin ja Rowsellin (emt.) visualisointi korostaa kotia ei-institutionaalisen kontekstin määrittävänä tekijänä. Tämä aiheuttaa perspektiiviharhan, sillä Pahldin ja Rowsellin näkökulmasta esimerkiksi lapsen populaarikulttuuria kohtaan osoittamat subjektiiviset mieltymykset ovat aina alisteisia perheen "kollektiiviselle maulle". Toinen ongelmakohta heidän mallissaan on oletus, jonka mukaan kolmannen tilan aktualisoituminen edellyttää ei-institutionaalisen kontekstin olemassaolon huomioimista institutionaalisessa kontekstissa sen käytäntöjen mukaisesti (emt., 65). Toisin sanoen lapsen täytyy tuoda ei-institutionaalinen aines esiin institutionaalisten käytänteiden kautta, jotta kolmas tila tulisi näkyväksi. Jos kolmatta tilaa kuitenkin tulkitaan siten, että siinä yksilö on identiteettinsä kautta yhtaikaisesti sekä ensimmäisessä että toisessa tilassa (Dredger ym. 2010; Hall 2005, 71; Moje ym. 2004; Wilson 2000), on kolmas tila olemassa myös yksilötasolla, vaikka sitä ei institutionaalisella tasolla hyödynnettäisi tai huomioitaisi.

Suomalaisen varhaiskasvatuksen mediakasvatuksen tilaa kartoittaneessa tutkimuksessa (Mediakasvatus... 2013) ilmeni, että vaikka mediamaailma mielletään yhdeksi lasten merkittävistä kasvu- ja oppimisympäristöistä, nähdään kasvattajan rooli ensisijaisesti turvallisen mediankäytön opastajana. Ajantasaista varhaiskasvatukseen suunnattua mediakasvatusmateriaalia on olemassa, mutta sen tuntemus on heikkoa. Materiaaleissa ja sisältöalueissa erityisen tärkeänä pidetään lasten suojelemiseen liittyvien aiheiden käsittelyä. Mediaa lasten omana itseilmaisun muotona ei nosteta samaan asemaan ja painetut kirjat nähdään varhaiskasvatuksen tärkeimpänä mediamuotona. (Emt, 6, 25-30.) Raportin havainnot ovat yhteneviä vuosina 2006-2007 toteutetun Mediamuffinssi-hankkeen arviointitulosten kanssa (Rantala 2011; Suoninen 2008, 20-21) Vastausten linja muistuttaa kuvausta traditionalistisesta, suojelevasta mediakasvatuskäsityksestä, jossa korostetaan korkeakulttuurin olevan populaarikulttuuria arvokkaampaa ja mediakasvatus nähdään lapsille annettavana rokotteena median haitallisia ja addiktoivia vaikutuksia vastaan. (Kellner \& Share 2005). Suojeludiskurssi on hallitsevassa asemassa myös kotimaisessa mediakasvatustutkimuksessa (Pekkala ym. 2013, 32). Pelkkään suojelutehtävään perustuva kolmannen tilan huomiointi on kuitenkin laadukkaan varhaiskasvatuksen näkökulmasta riittämätön lähtökohta. Tämä todetaan myös esiopetuksen opetussuunnitelman perusteissa $(2010,7,11)$ :

Lapsen kieli- ja kulttuuri-identiteetti sekä hänen kykynsä ilmaista itseään monipuolisesti vahvistuvat ja kehittyvät. Hän tutustuu eri taidemuotoihin, paikalliseen ja kansalliseen kulttuuriin sekä mahdollisuuksien mukaan myös muihin kulttuureihin - -. Lapsen omien tutkimusten lähtökohtana ovat lapsen elinympäristöön läheisesti liittyvät ilmiöt ja tapahtumat sekä niistä saadut kokemukset.

Kieli- ja kulttuuri-identiteettiä ei tule rajata käsittämään vain korkeakulttuuria ja kirjakieltä, eivätkä arvokkaiksi mielletyt tekstilähteet ja -tuotteet saa perustua vain aikuisten määrittämiin arvoasetelmiin (ks. Haas Dyson 2010; Vasquez 2004). Kun kasvattaja yrittää sulkea lasten mediakulttuurin pois kasvatustyöstä, syntyy kahden kult- 
tuurin ongelma, joka saattaa näyttäytyä motivaation puutteena ja pahimmillaan jopa lasten ja kasvattajien pahoinvointina (Niinistö \& Ruhala 2007, 124; Pennanen 2009, 196-202). Vuorisalo $(2013,127)$ toteaakin osuvasti, että päiväkodin "[o]hjatun toiminnan kentällä on jännite, joka syntyy siitä, että opettajat tuottavat sinne ohjatulla toiminnalla tietyn sisällön, johon lasten oma toiminta törmää".

Sama jännitteisyys voi ilmetä sekä kotona että päiväkodissa. Marjatta Kalliala kuvaa kuusivuotiaan pojan tilannetta vanhempien ja vertaistovereiden päinvastaisten lelupreferenssinäkemysten keskellä: vanhemmat eivät suostu ostamaan pojalleen ikätovereiden suosimia Power Rangers -hahmoja ja leimaavat ne turhaksi roskaksi. Päiväkodissa poika kuitenkin leikkii säännöllisesti roolileikkejä, jotka perustuvat kyseisiin hahmoihin. Hän tosin pystyy osallistumaan leikkiin vain asettuessaan vapaaehtoisesti pienempään rooliin ja toimiessaan leikkiä johtavien ja leikkiteeman parhaiten tuntemien lasten antamien yksityiskohtaisten ohjeiden mukaisesti. (Kalliala 1999, 103, 128-134, 171-173, 190.) Yllä kuvatussa tilanteessa lapsi siis tuo ei-institutionaalisesta kontekstista mukanaan aineksia, jotka eivät ole osa perheen omaa kulttuuria (vrt. Pahl \& Kelly 2005). Lapsi myös käyttää aineksia institutionaalisessa kontekstissa toiminnassa, jota ei kuitenkaan lueta formaalin kasvatuksen alle. Tämä kertoo siitä, että vaikka poikien leikki tapahtuu ajallisesti ja paikallisesti institutionaalisen kasvatuksen piirissä ja leikki toimintana on esiopetuksen opetussuunnitelman perusteiden keskiössä (Opetushallitus 2010, 10), kyse on pohjimmiltaan alakulttuurista. Kamppailuleikit sekä aggressioon ja väkivaltaan viittaavat yksityiskohtaiset mediaviitteet ovat kuitenkin päiväkotikontekstissa ei-toivottuja ilmiöitä ja sellaisina tuskin päiväkodin henkilöstön tietoisesti ja tavoitteellisesti herättelemiä tai tukemia (ks. Pennanen 2009, 196-205; Trageton 2007, 189-190).

Tämän jännitteen huomioon ottaminen palauttaa kolmannen tilan käsitteen lähemmäs sen juuria eli Wilsonin (2000) Bhabhan (1994) ja Gleen (1990) kriittisiin näkökulmiin nojaavaa tulkintaa kolmannesta tilasta. Jotta myös Kupiaisen (2007b) mallinnus tavoittaisi jännitteen, visualisontiin tulisi sisällyttää myös ei-institutionaalisten mikroympäristöjen moninaisuus ja mikroympäristöjen (ks. Pahl \& Kelly 2005) suhteisuus, eli niiden väliset mahdolliset ristiriidat, jännitteet. Kehittämällä mallinnusta tähän suuntaan, sen avulla kyettäisiin tarttumaan käsitteellisesti paremmin subjektitasolla tapahtuvaan lasten itsensä laajempien rakenteiden sisälle luomaan alakulttuuriin. Pennanen (2009, 196-202) luonnehtiikin medialeikkejä aikamme kielletyiksi leikeiksi: lapset leikkivät näitä leikkejä piilossa, he naamioivat leikkinsä tunnistamattomiksi, he luopuvat niistä alistuen tai vastustavat aikuisten valtaa ja kontrollipyrkimyksiä leikkimällä niitä tietoisesti ja näkyvästi. Kuten mikään muukaan kasvatusinstituutio, esiopetus ei ole puhtaan rationaalinen toimintaympäristö, vaan tuntevien ja kokevien subjektien moniääninen kohtauspaikka (ks. Elbaz-Luwsich ym. 2002, 197). Myös opettaja tuo kolmanteen tilaan mukanaan subjektiiviset näkemyksensä ja arvonsa, oman ei-institutionaalisen kontekstinsa. Tämä on ilmiö, jota ei aiemmissa kolmatta tilaa käsittelevissä tutkimuksissa ole riittävästi huomioitu'. Opettaja on työssään moraalinen toimija, tahtoipa hän sitä tai ei. Hän myös edustaa oppilailleen eettistä toimijaa, jonka arvot ja näkemykset ovat yleispiirteissään samoja kuin yhteiskunnassa yleensä 
hyväksytyt arvot ja toiminnan ideaalit. (Uusikylä 2002, 10; Suoranta 2003, 124-125.) Kolmannen tilan identiteettiperustaisessa määrittelyssä affektiota ei voi irrottaa kohteesta tai kokijasta. Tämän vuoksi opettajan suhde lapselle tärkeään mediakulttuuriseen ilmiöön on osa opettajan ja lapsen välistä kokonaissuhdetta, jossa opettajan arvostava tai mitätöivä arvio lapselle merkityksellistä mediailmiöistä kohdistuu myös lapsen kokemukseen ja lapsen identiteettiin (ks. Rintakorpi 208, 109). Aiemmista mallinnuksista poiketen sisällytän visualisointiin ympäristöjen sisäiset mikrokontekstit ja niiden väliset relaatiot, jotka voivat olla näkemyksiltään saman- tai erisuuntaisia. Varhaiskasvatuksen viitekehyksessä mikrokonteksteja voivat olla perhe, esiopetusryhmän ulkopuolinen vertaisryhmä (esim. harrastustoiminnan kautta), esiopetusryhmän vertaisryhmä ja esiopetushenkilöstö.

Kuvio 3. Kolmas tila

\section{Ei-institutionaalinen kasvu- ja oppimisympäristö}

Institutionaalinen kasvu- ja oppimisympäristö

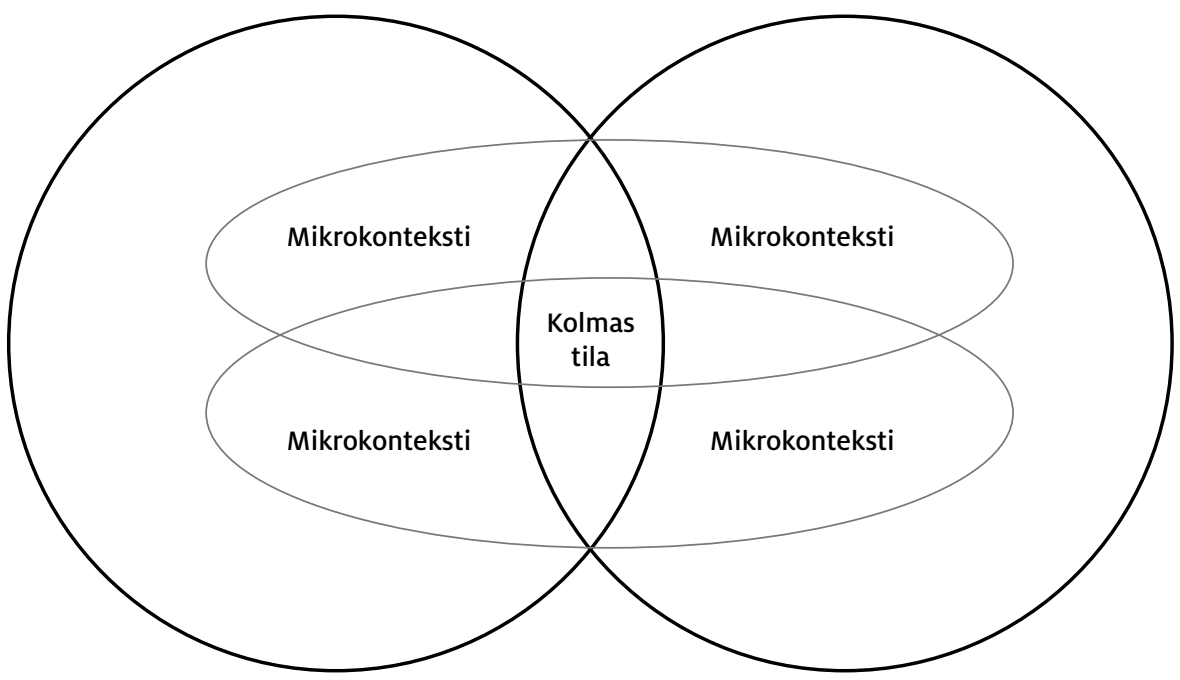

Kolmas tila ei siis ole yhtenäinen tila vaan joukko tiloja, jotka voivat olla harmonisia tai jännitteisiä. Lapset voivat luoda leikkien kautta kolmansia tiloja, joista aikuiset eivät ole tietoisia (Karimäki 2007, 46; Pennanen 2009). Toisaalta kasvattajat voivat nähdä mediakulttuurin pedagogisena resurssina, jota he uudelleenkontekstualisoinnin keinoin hyödyntävät tuoden lapselle merkitykselliset mediatekstit tavoitteellisesti ja tietoisesti uuteen tilanteeseen osaksi institutionaalista kasvatusta. Lapsen mediatodellisuuden huomioiva ja lasta kuunteleva ja osallistava mediakasvatus on lapsuudelle mahdollisuus eikä uhka. (Korkeamäki 2011b, 46, 49; Niinistö \& Ruhala 2007, 124; Niinistö \& Sintonen 2007, 27; Pääjärvi \& Sommers-Piiroinen 2013; Vasquez 2004, 202203.) Tätä tarkastelen seuraavaksi kirjoittamisen näkökulmasta. 


\section{Kirjoittaminen, kolmas tila ja institutionaalinen (varhais)kasvatus}

Lasten formaalien kasvatusympäristöjen ulkopuolinen tekstimaailma on sisällöltään ja käytänteiltään monimuotoinen ja -mediainen (Suoninen 2014). Tyypillisessä kasvatusinstituution tekstitapahtumassa lapsi kuitenkin istuu pöydän äärellä, työskentelee kynää ja paperia käyttäen tehden ennalta suunniteltuja tehtäviä. Tehtävien ja toiminnan rakenne on lineaarinen: ylhäältä alas ja vasemmalta oikealle. (Jokinen ym. 2013). Käynnissä on kuitenkin siirtymä kohti sukeutuvaan oppimiseen ja kehitykseen suuntautuvaa pedagogiikkaa, jossa lapsen ja tekstiympäristöjen kohtaaminen johtaa konventionaalisen lukutaidon kehittymiseen ja jossa oppimista tulee tukea mahdollisimman luonnollisissa tekstiympäristöissä niin, että myös leikisti lukeminen ja kirjoittaminen nähdään arvokkaana ja oppimiseen kuuluvana prosessina. (Gerde ym. 2012; Korkeamäki 2011a, 14.)

Välinetasolla kirjoittamisen ei tarvitse rajoittua vain kynäsuoritteisiin, sillä ruudulle tuotettavat ja ruudulta luettavat tekstit ovat merkittävä osa nykylasten tekstiympäristöjä (Gerde ym. 2012; Suoninen 2014, 63). Toiminnan tasolla tekstitapahtumia voidaan tuoda osaksi lasten leikkejä (Graham 2001) tai oppimisympäristöön voidaan luoda spontaanin kirjoittamisen mahdollistavia tarjoumia (Lindahl \& Folkeson 2012). Sisältötasolla määriteltyjen aiheiden sijaan lasten voidaan antaa kirjoittaa heitä itseään kiinnostavista teemoista (Trageton 2007; Vera 2011). Haas Dysonin (2003; 2010) tutkimuksissa lapset ammensivat toistuvasti vapaiden kirjoitustehtävien teemat heille tutuista aiheista, kuten elokuvista ja sarjakuvastripeistä. Sijoittamalla tärkeitä elementtejä tutuista konteksteista uuteen ja vieraaseen toimintamuotoon he tekivät kasvatusinstituutiossa tapahtuvasta kirjoittamisesta merkityksellistä. Yhteisötasolla kirjoittaminen on tarkoitushakuista sosiaalista toimintaa, jaettavaan muotoon taltioituja ideoita, näkemyksiä ja mielipiteitä. (Gerde ym. 2012; Ivanic 2004.) Suojeludiskurssin myötä kolmas tila muodostuu kuitenkin usein jännitteiseksi myös tekstitapahtumien ja -ympäristöjen suhteen. Marsh (2003) toteaakin, että polut osallistuvaan kirjalliseen kulttuuriin voitaisiin päällystää lasten itsensä tärkeiksi katsomilla aihioilla. Ideologisesti määrittyneet käsitykset siitä, millaisia ovat lapsuuteen kuuluvat arvokkaat tekstit kuitenkin vaikeuttavat vaihtoehtoisten tekstityyppien valikoitumista osaksi formaalien oppimisympäristöjen käytänteitä. (Haas Dyson 2010; ks. Marsh 2006.)

\section{Tutkimuksen toteutus}

Tutkimukseen osallistui 27 lasta, joista tyttöjä oli 12 ja poikia 15. lältään lapset olivat kuusi- ja seitsemänvuotiaita. Lasten huoltajilta ja lapsilta itseltään pyydettiin lupa saada hyödyntää lasten tuottamia kirjoituksia tutkimuskäytössä. Tytöistä 10 ja pojista 7 oli tutkimuksen alussa luku- ja kirjoitustaitoisia. Jokainen lapsista osasi kirjoittaa oman nimensä. Aineisto on tuotettu päiväkodin yhteydessä toimivassa esiopetusryhmässä tammi- ja toukokuun välisenä aikana vuonna 2012. Tutkija toimi yhtenä ryh- 
män opettajista. Tietokoneet (3 kpl.) oli sijoitettu esiopetustilan yhteydessä olevaan kirjastoon niin, että jokaisen koneen äären mahtui useampi lapsi. Kirjaston yhteydessä sijaitsi myös alakerran pikkuhuoneeksi kutsuttu leikkitila. Tietokonepaikka ei siis ollut muusta toiminnasta erillinen "laboratorio", vaan kirjoittaminen rinnastettiin toimintana vapaaseen leikkiin, ja se oli mahdollista aina kun käynnissä ei ollut sitä estävää ohjattua toimintaa tai arkirutiineja, kuten ruokailua ja ulkoilua (ks. Gerde ym. 2012; Palmgren-Neuvonen ym. 2011, 38). Kirjoitukset on toisin sanoen tuotettu formaalin kasvatusinstituution piirissä, mutta informaaleissa tilanteissa, ja kirjoittaminen on kummunnut lasten omasta halusta. Näin ollen toimintamallissa toteutuvat aiemmin välineelle, toiminnalle, sisällölle ja yhteisölle määritellyt luonnollisuuden kriteerit. Ohjeistus vapaaseen kirjoittamiseen oli pääpiirteittäin seuraava: Kirjastossa on kolme tietokonetta käytössä kirjoittamista varten. Kerro aikuiselle kun menet kirjoittamaan ja pyydä aikuista tallentamaan kirjoitus kun haluat lopettaa. Kirjoita aina ensimmäiseksi oma nimesi ja päivämäärä. Lapset saivat valita, jatkavatko he aiemmin aloittamaansa kirjoitusta vai aloittavatko uuden. Verkkoyhteyden puutteen vuoksi kirjoitukset tallennettiin USB-muistitikulle. Osa lapsista toi kotoa mukanaan oman tikun. Lisäksi käytössä oli yksi yhteinen tikku.

Tutkimuksen alkuperäisenä tarkoituksena oli selvittää, mistä esiopetusikäiset lapset kirjoittavat saadessaan kirjoittaa vapaasti tietokoneella. Pian aineisto alkoi kuitenkin antaa viitteitä kolmanteen tilaan ja siinä ilmenevään suhteisuuteen ja mahdollisiin jännitteisiin. Hermeneuttisen, absoluuttisen alku- ja päätepisteen hylkäävän tulkintaprosessin mukaisesti tutkimuskysymys muutti muotoaan matkan varrella (Siljander 1988, 115-119). Tähän hetkeen pysäytettynä tutkimuskysymys tarkentui muotoon: Millaisia, keiden välisiä ja miten ilmaistuja suhteita lapset julkituovat kirjoituksissaan kolmannen tilan kautta?

\section{Tulokset}

Lapset tuottivat aineistonkeruuperiodin aikana 207 erillistä tallennusta, jotka sisälsivät 189751 merkkiä (ilman välilyöntejä). Merkeistä 65782 oli prosessoituja, satunnaiselle lukijalle avautuvia merkki- tai merkkijonoyhdistelmiä. Esiopetuskontekstin ulkopuolisten ilmiöiden rooli lasten kirjoitusten sisällöissä oli merkittävä. Esiopetuskontekstin ohjattuun toiminnalliseen ulottuvuuteen palautettavia kirjoituksia oli ainoastaan neljä kappaletta: Kolme poikaa kirjoitti kaksi toimintasuunnitelmaa opettajan kanssa yhdessä toteutetusta, lasten ideasta käynnistyneestä suihkumoottoripolkupyörän rakennusprojektista. Kaksi poikaa laati puolestaan yhteisen selonteon päiväkodin lähitien liikennemäärästä. Kirjoitus perustui opettajan kanssa tehtyyn liikenteenlaskentaprojektiin. Lisäksi yksi tyttö kirjoitti muistinvaraisesti "luu, kuu, puu"-sanat, jotka voidaan jäljittää aiemmin samana päivänä läpikäytyihin alkuäänneharjoitteisiin. Esiopetustilojen fyysisestä ympäristöstä poimittuja vihjeitä löytyi kymmenestä (10) tallennuksesta. Nämä olivat tyypillisesti kirjoista ja seinillä olevista julisteista kopioituja sanoja ja lauseita (Gerde ym. 2012; Makkonen 2005). Korkeamä- 
keä (1996; 2011b, 48) mukaillen ystävien nimien kirjoittamista ei tässä tulkita esiopetuskontekstista ammentavien vihjeiden hyödyntämiseksi. Esiopetushenkilöstön nimiä löytyi kolmesta tallennuksesta. Kirjoitusnäytteet, joihin tulen jatkossa viittamaan, löytyvät taulukosta 1.

Taulukko 1. Kirjoitusnäytteet

\begin{tabular}{|c|c|}
\hline $\begin{array}{l}\text { Näyte 1: } \\
\text { lukeva tyttö (Anna) }\end{array}$ & $\begin{array}{l}\text { SIIRI JA TIINA LEIKKI VÄT YHDESSÄ VINTILLÄ KUN ANNA TULI } \\
\text { KESKEYTTÄMÄÄN LEIKIN JA SANOI TYTÖILLE LÄHDETÄÄN LOMALLE JEE } \\
\text { TYTÖT HUUSIVAT MINNE LÄHDETÄÄN ESPANIAAN JES KAIKKI HUUSI VAT } \\
\text { JA HALASIVAT ANNAA ... }\end{array}$ \\
\hline $\begin{array}{l}\text { Näyte 2: } \\
\text { ei-lukeva ja lukeva } \\
\text { poika (Keijo ja } \\
\text { Jaakko) }\end{array}$ & HAETAAN SALAA LONPAKOT KOTOA LELUTAPULI PARHAAT LEGOT \\
\hline $\begin{array}{l}\text { Näyte 3: } \\
\text { lukeva poika (Sami) }\end{array}$ & $\begin{array}{l}\text { SAMIJAEEMELIONKIVOJAISISTÄJANEONKIVOJAMYÖSTOISISTA } \\
\text { NELEIKI YHDESÄANRYBIRTSIÄ }\end{array}$ \\
\hline $\begin{array}{l}\text { Näyte 4: } \\
\text { lukeva poika (Matti) }\end{array}$ & $\begin{array}{l}\text { AKU ANKKA OLI VALMIINA TAISTELEMAAN MATTIA VASTAAN. MATTI } \\
\text { KOMENSI AKU ANKAN TAISTELEMAAN HETI HÄNTÄ VASTAAN. }\end{array}$ \\
\hline $\begin{array}{l}\text { Näyte } 5: \\
\text { lukeva poika }\end{array}$ & $\begin{array}{l}\text { ANKKALINNASSA OLI NÄINÄ ÖINÄ TAPAHTUNUT KUMMIA JOS } \\
\text { HALUAMME TIETÄÄ MITEN SE ALKOI MEIDÄN PITÄÄ HYPÄTÄ } 2 \text { VIIKKOA } \\
\text { TAAKSEPÄIN ... }\end{array}$ \\
\hline $\begin{array}{l}\text { Näyte 6: } \\
\text { kaksi lukevaa tyttöä }\end{array}$ & $\begin{array}{l}\text {...KOLMANTENA PÄIVÄNÄ NAPERO JA PIKKU LOHI KÄÄRME KINASTELIVAT } \\
\text { KUMPI KASVATTAA PAREMMAN KASVIN MUTTA NAPERO SANOI ETTÄ EI } \\
\text { ENÄÄ KINASTELLA... }\end{array}$ \\
\hline $\begin{array}{l}\text { Näyte } 7 \text { : } \\
\text { ei-lukeva poika } \\
\text { (Keijo) }\end{array}$ & $\begin{array}{l}\text { LEGOSURGE } \\
\text { LEGOPLITFEIS }\end{array}$ \\
\hline $\begin{array}{l}\text { Näyte 8: } \\
\text { lukeva poika (Jaakko) }\end{array}$ & $\begin{array}{l}\text { HERO FAGTORY SURGE } \\
\text { HERO FAGTORY PITFEIS }\end{array}$ \\
\hline $\begin{array}{l}\text { Näyte 9: } \\
\text { lukeva poika } \\
\text { (Jaakko) }\end{array}$ & $\begin{array}{l}\text { ANGRY BIRDS OLIPA KERRAN SININEN JA KELTANEN JA PUNAINEN JA } \\
\text { PUNAISEN ISÄ } \\
\text { HEILLÄ OLI MUNAT JA POSSUT HALUSI MUNAT JA POSSUT AATELIVAT } \\
\text { VARSTAA MUNAT JA POSSUT OTTIVAT VALEASUT JA MENIVÄT } \\
\text { ANGRY BIRDSJEN LUO HAKEMAAN MUNAT ANGRY BIRDSIT NUKKUIVAT } \\
\text { KUN ANGRY BIRDSIT HERÄSIVÄT HEHUOMASIVAT ETTÄ MUNAT ON } \\
\text { VARASTETTU ANGRYT SUUTTUIVAT AMMPUI RITSALLA POSSUJEN LINNAN } \\
\text { EKATULI POMMI JA SITTEN TULI SININEN JA SITTEN TULI PUNAISEN ISÄ } \\
\text { ANGRY BIRDSIT SAI MUNAT LUPPUI }\end{array}$ \\
\hline $\begin{array}{l}\text { Näyte 10: } \\
\text { ei-lukeva poika }\end{array}$ & ESAJAARIJAISIJAÄTITJAVILHOJAANTTIJASAMI \\
\hline
\end{tabular}

Kolmas tila esiintyi kirjoituksissa kahdessa muodossa. Uudelleenkontekstualisoinnin kohteena oli joko oma lähipiiri tai mediatekstit. Oman lähipiirin, ystävien perheiden ja sukulaisten sijoittaminen kirjoituksiin tapahtui usein sanalistojen muodossa. Tytöt sijoittivat usein itsensä, ystävänsä ja perheensä myös toimijoiksi tarinoihin, joiden tapahtumat ja toimijoiden väliset relaatiot eivät olleet todellisuuspohjaisia (näyte 
1). Poikien kirjoituksista löytyi vain kaksi tätä kategoriaa edustavaa tuotosta (näyte 2). Sekä poikien että tyttöjen kirjoituksista löytyi lisäksi muutamia otteita, joiden voidaan tulkita kuvaavan todellisuutta vailla keksittyä lisää. Niissä käsiteltiin yleensä ystävien ja perheenjäsenten välistä kiintymystä (näyte 3). Kirjoitukset, poislukien ne joissa lukutaidoton kirjoittaja oli jäljentänyt lauseita suoraan kirjasta, eivät olleet kopioita tai sävyttömiä toisintoja jo olemassa olevista mediateksteistä. Lapset saattoivat sijoittaa itsensä toimijaksi mediasta tuttujen hahmojen joukkoon (näyte 4) tai kirjoittaa lähdeaineiston kieltä, henkilöhahmogalleriaa ja näiden relaatioita mukailevia, mutta persoonallisia kertomuksia (näyte 5). Alun perin ei-kirjallisessa muodossa olevat mediaviitteet toteutettiin omaleimaisina onomatopoeettisina merkkijonoina. Esimerkiksi yhteen kahden tytön yhteiskirjoitukseen (lukeva ja lukutaidoton) oli rekonstruoitu Robinin Frontside ollie -hitin sävel- ja rytmimaailmaa muodossa "vooooou titi titi vooooou titi". Osa lapsista kirjoitti jatkokertomuksia, joiden erilliset osat nimettiin jaksoiksi. Mediaviitteiden monikerroksellisuuden ja uudelleenkontekstualisaation suhteen pisimmälle ja abstrakteimmalle tasolle viety aihe oli Napero, yhden tytöistä jo ennen esiopetusvuotta keksimä rooli, kuvitteellisen lastenohjelman kuvitteellinen hahmo. Napero oli suosittu leikkiteema koko toimintavuoden ajan ja hahmo esiintyy neljässä kirjoituksessa kolmen eri kirjoittajan kuvaamana (näyte 6).

Mediakulttuuristen viitteiden määrä ei ole sinänsä yllättävä ilmiö, eliväthän samat hahmot jo omaa elämäänsä lasten leikeissä ja piirroksissa. Koska valmiiden tarinoiden tuotteistamisen on yhä keskeisempi osa modernia leikkikaluteollisuutta, samat mediahahmot näyttelevät lasten elämässä montaa eri roolia useassa muodossa. (Kalliala 1999, 155; Laukka 2004, 391). Esimerkiksi poikien kirjoituksissa toistunut Star Wars -teema perustunee LEGO: ${ }^{\text {TM }}$ lanseeraamaan Star Wars Lego -sarjaan, joka yhdessä Pirates of Caribbean ja Indiana Jones -legosarjojen kanssa on uudelleenkontekstualisoinut vanhemmille lapsille, nuorille ja aikuisille suunnattua viihdettä nuoremmille kuluttajille (ks. kuvio 5. $)^{2}$. Useat tyttöjen kirjoituksista taas alkoivat Disney esittää TV-sarjan innoittamana nimi esittää -fraasilla (esim. Minna esittää), jota seurasi joko sisältöä kuvaava otsikko tai varsinainen sisältö (ks. Evans 2002). Kupiainen (2007a, 17) toteaakin, että tyttöjen elämismaailma on lokaalisti ja globaalisti vahvasti Disneyn kyllästämä. Poikien kirjoituksissa usein käsiteltyä Aku Ankkaa voidaan taas pitää suomessa jo lähes kansallisena instituutiona (Heiskanen 2007, 93). Disney-vaikutteet, joskin keskenään hyvin erilaiset, olivatkin aineiston ainoa selkeästi ei-sukupuolittunut medialähde.

Mediaviitteiden sukupuolisidonnaisuus myötäilee tuoreimmassa mediabarometrissa (Suoninen 2014, 65-66) tehtyä havaintoa o-8-vuotiaiden lasten mediasisältöjen sukupuolittuneesta eriytyneisyydestä. Poikien on myös havaittu olevan leikkikaluvalinnoissaan 4-vuotiaasta alkaen vahvan tietoisia sopivista, maskuliinisista leikkikaluista (Blakemore \& Centrers 2005) Tytöt taas valitsevat helpommin myös neutraaleja ja maltillisen maskuliinisia leikkikaluja (Downs 1983). Niin ikään lasten leikkikaluvalintojen on havaittu perustuvan osittain leikkikalun luomaan potentiaaliin yhteisleikistä (Mertala ym. 2014). Myös Haas Dysonin (2010) tutkimuksessa lasten sukupuolittuneet leikkiteemat näkyivät kirjoitusten eriytyneissä teemoissa. Tosinaan nousee esiin myös molempia sukupuolia innostavia mediakulttuurisia teemoja (Haas Dyson 2003; Suoninen 2014, 
68). Tässä tutkimuksessa tosin tyttöjen leikeissä ja piirroksissa osoittama mielenkiinto Angry Birds -hahmoja kohtaan ei toistunut kirjoituksissa kuin yhdessä lukutaitoisen tytön ja lukutaitoisen pojan yhteiskirjoituksessa. Sukupuolittuneisuus näkyi tässäkin kirjoituksessa siinä, että kyseessä oli muuten pojille ominaiseksi osoittautunut Angry Birds -tarina, mutta sillä erolla, että lintuperheen feminiinit hahmot (esim. vaaleanpunainen Stella) otettiin hahmogallerian osaksi harvoin mukana olevina tyttöystävinä.

Sukupuolittuneet teemat voidaan tulkita osoitukseksi siitä, että kirjoittaminen on sosiaalinen käytäntö (Ivanic 2004). Yhdenmukaisten keskusteemojen ympärillä pysytteleminen ja kopiointi heijastavat jaetun kiinnostuksen kohteen kautta suhteisuutta, kuten ystävyyttä, eli toiminta on tarkoituksenmukaisesti koordinoitua. (Haas Dyson 2010). Tästä kertoo se, että 27 lapsen ryhmässä olisi mahdollista muodostaa 358 suhdetta, mutta kaikki niistä eivät toteudu. Pääsääntöisesti leikit tapahtuvat vakiintuneissa ja sukupuolijakaumaltaan homogeenisissä ryhmissä. (Vuorisalo 2013, 130-131, 133-134; ks. kuvio 4.) Edellä läpikäydyn Angry Birds -tarinan poikkeava kirjoittajapari selittyy sillä, ettei totuttuja ryhmiä ollut mahdollista muodostaa. Kirjoitus ajoittui hiihtolomaviikolle, jolloin paikalla oli vain murto-osa koko lapsiryhmästä ja vakiintuneiden ryhmien sijaan lapset muodostivat uusia, väliaikaisia ryhmittymiä.

Vakiintuneita kirjoittajakoalitioita tarkastelen Keijon (ei-lukeva) ja Jaakon (lukeva) yhteistyön kautta. Poikien kirjoittaessa yhdessä, he kirjoittivat pääasiallisesti sanalistoja, joiden keskusteema olivat ne lelut, joista he pitivät (näytteet 7 ja 8). Kirjoittaessaan ilman Keijoa Jaakon tuotokset olivat kertomusmuotoisia (näyte 9). Vakiintuneen kanssakirjoittajan läsnä- tai poissaololla oli huomattava merkitys sille, miten kompleksisista sisältöä pojat pystyivät tuottamaan. IIman Jaakon luku- ja kirjoitustaitoa sekä samaan kohteeseen suuntautunutta kiinnostusta, Keijo ei olisi pystynyt kirjoittamaan sanatasoisesti ilman mallia, mutta toimiessaan Keijon tukijana, Jaakko "tyytyi" kirjoittamaan niin ikään sanatasoisesti.

Sosiaaliset suhteet ilmenivät kirjoittajaparien lisäksi kirjoitusten sisällöissä. Jaettujen mediaviitteiden lisäksi viitteet affektiosta saattavat olla myös suoraviivaisempia. Paperille kirjoitetut vertaisten nimet eivät ole sattumanvaraisia vaan kertovat kiintymyksestä, jo olemassa olevista tai toivotuista ystävyyssuhteista (näyte 10). Tosinaan affektio ilmaistiin suorasanaisesti (näyte 3). Huomionarvoista on, että yhdessäkään tallennuksessa ei kirjoitettu vertaisista mitään negatiivista. Toisaalta myös nimen kirjoittamatta jättäminen voi olla intentionaalinen loukkaus, etenkin jos kyseinen lapsi on samassa tilassa ja tietoinen siitä, millä perusteella nimiä listaan kirjoitetaan. (Ks. Haas Dyson 2010.) Valitettavasti tekstejä analysoimalla sosiaalista kirjoitustapahtumaa ei voi tältä osin täysin rekonstruoida. Niin ikään kirjoittajien nimien kirjaaminen asiakirjaan ei kykene tavoittamaan kirjoitustapahtumien sosiaalista monimuotoisuutta, sitä miten lapsen kulkivat tilaan, tilassa ja tilasta pois kommentoiden samalla toistensa tekemisiä (ks. Ivanic 2004; Viljamaa 2012).

Lasten vertaisnimeämiset on mallinnettu kuvioon 4. Vuorisalon (2013, 130-131, 133-134) havaintojen mukaisesti lapset kirjoittivat pääasiassa samaa sukupuolta olevien vertaisten nimiä töihinsä. Tyttöjen suhdeverkosto sisältää pokia enemmän vastavuoroisia mainintoja. Yksi syy tähän on tyttöjen suosima tapa sijoittaa itsensä ja 
ystävänsä kertomustensa päähenkilöiksi. Kolme tytön kirjoitukset eivät sisältäneet yhtään nimeä, ja myöskään heitä ei mainittu yhdessäkään kirjoituksessa. Lasten vertaisnimeämisen ja jaettujen mediaviitteiden muodostamaa suhteisuuden kudelmaa havainnollistan puolestaan kuviossa 5.

Kuvio 4. Lasten vertaisnimeämiset

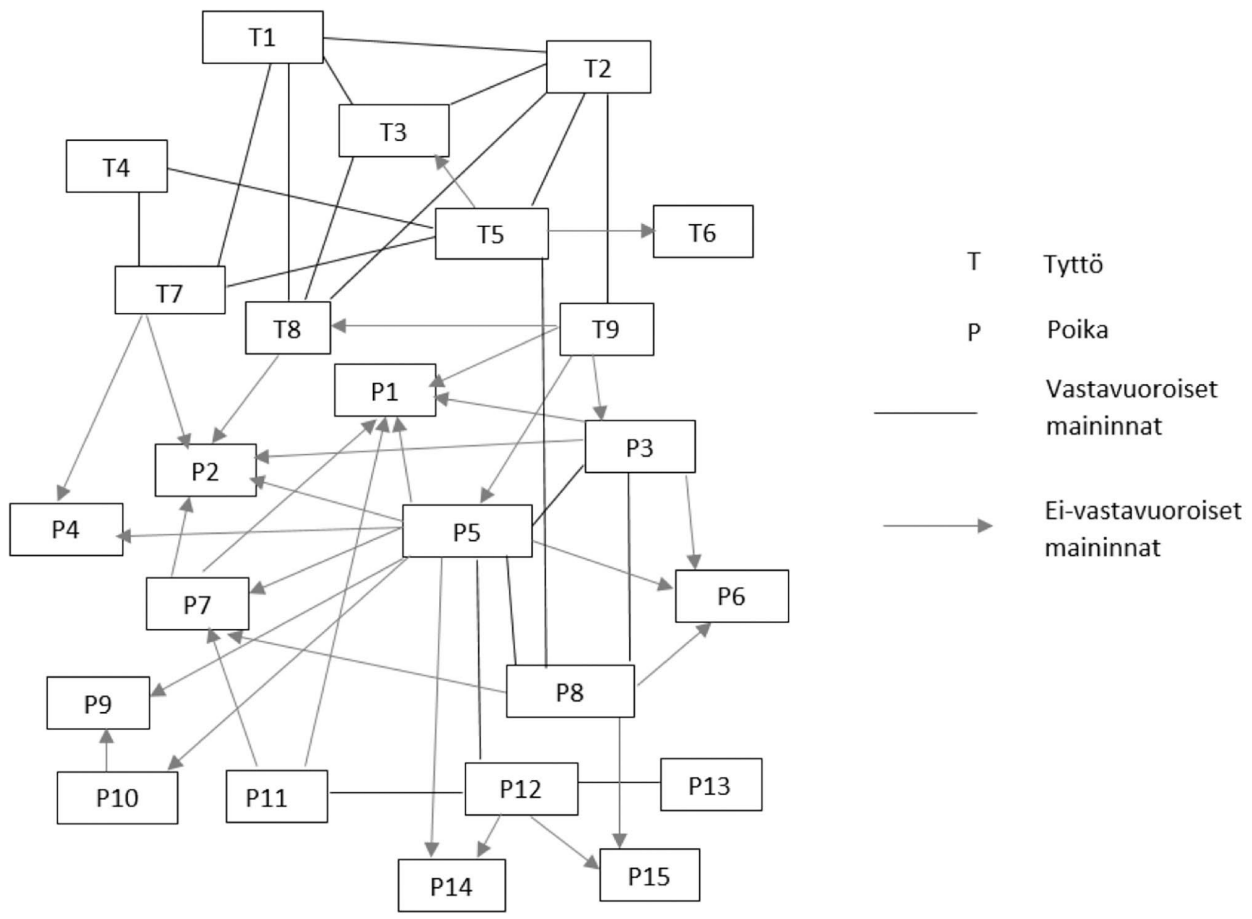

Kuvio 5. Esimerkki vertaisnimeämisten ja mediaviitteiden kudelmasta

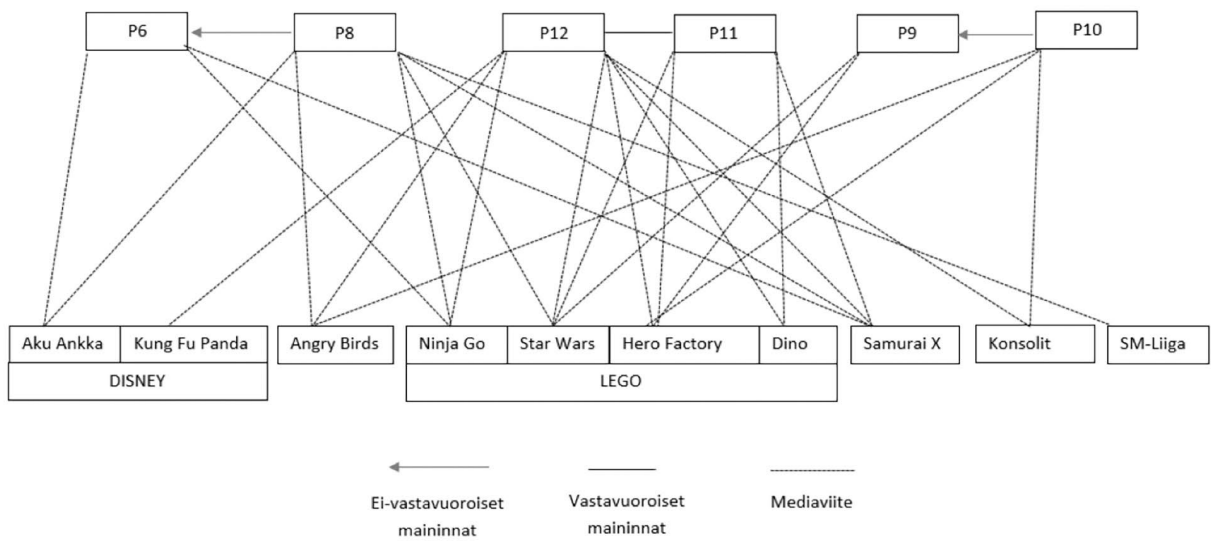


Kirjoituksissa esiintyneiden lasten välittömään kokemusmaailmaan kuuluvien henkilöiden, ystävien ja perheen roolit ja relaatiot elivät kirjoituksissa omalakista elämäänsä. Haas Dyson (2003) kutsuu tätä ilmiötä virallisen ja epävirallisen maailman väliseksi jännitteeksi. Hänen tutkimuksessaan kaverukset saattoivat piirroksissaan ja kirjoituksissaan kertoa, että kävivät säännöllisesti toistensa luona leikkimässä, mutta vanhemmilta kysyttäessä tällaista ei ollut koskaan tapahtunut. Aineistossani tämä on ominaista tyttöjen kirjoituksille, joiden yksi keskeinen teema oli vapaa-aika, kesä ja lomailu. Suvilehto (2008, 78-79) nimeää nämä matkakertomuksiksi, lastenkirjallisuuden peruskliseistä ammentaviksi kepeiksi tarinoiksi, joissa uidaan, syödään ja katsellaan nähtävyyksiä (näyte 1). Oma ainutkertainen ja kiehtova esimerkkinsä on Keijon ja Jaakon kirjoittama katkelma, jossa he suunnittelevat hakevansa salaa lompakot kotoa ja menevänsä paikalliseen lelukauppaan ostamaan legoja (näyte 2). Kahdesta tallennuksesta löytyvien WC-merkkiyhdistelmää toistavien merkkijonojen lisäksi tämä ote oli ainoa sekä kodin että mediamyönteisen esiopetuskontekstin arvojen tai normien vastainen, alakulttuurisen ja jännitteisen kolmannen tilan luova kirjoitus. On toki mahdollista ja jopa todennäköistä, että alakulttuurisia kirjoituksia on kirjoitettu enemmänkin, mutta niitä ei vain ole tallennettu lasten ollessa tietoisia päiväkodin normeista. Yhteenvetona voidaan todeta, että kolmannessa tilassa ilmaistut suhteet olivat myönteisiä ja kohdistuivat pääosin vertaisiin. Suhde toiseen subjektiin ilmaistiin joko suoraan nimeämällä tai epäsuorasti jaetun, usein mediakulttuurista ammentaneen keskusteeman kautta. Sekä suorat että epäsuorat ilmaukset olivat kohteiltaan ja aiheiltaan leikkiteemojen tapaan sukupuolittuneita.

\section{Lopuksi}

Olen artikkelissani pyrkinyt tarkentamaan kolmannen tilan käsitettä suhteisuuden näkökulmasta sisällyttämällä siihen eri toimintakonteksteissa operoivat mikrokontekstit ja niiden väliset saman- ja erisuuntaisuudet siinä, mikä mielletään soveliaaksi ja arvokkaaksi. Samansuuntaiset tulkinnat muodostavat harmonisen kolmannen tilan, erisuuntaiset puolestaan jännitteisen. Konkreettisena viitekehyksenä olen käyttänyt esiopetuskontekstissa vapaan leikin aikana tuotettuja kirjoituksia. On muistettava, että lasten kerronta, kirjoitukset mukaan lukien, ei synny kulttuurisessa tyhjiössä (ks. Viljamaa 2012). Mediakasvatus kuntien varhaiskasvatuksessa (2013) -raporttiin viitaten tutkimusesiopetusryhmän ilmapiiriä voidaan luonnehtia poikkeuksellisen mediamyönteiseksi (vrt. Pennanen 2009). Makkosen $(2005,64,107)$ mukaan ryhmän yleisen ilmapiirin ja opettajan työtapojen onkin nähty ohjaavan lasten toimintaa epäsuorasti. Tutkimusryhmässä lapsille tärkeät mediakulttuurihahmot olivat osa oppimisympäristöä piirustus- ja väritystehtävinä, askartelujen ja kädentöiden aiheina, itsetehtyinä rooliasuina ja figuureina sekä draamaa hyödyntävien toimintojen teemoina. Tämä vaikuttaa luonnollisesti siihen, millaisia kirjoituksia lapset kirjoittivat ja millaisen kolmannen tilan ne muodostavat - harmonisen vai jännitteisen. Jos sama aineisto olisi sijoitettu suojeludiskurssia toteuttavaan kontekstiin, ratkaisu olisi luonut tilasta tutki- 
musryhmän tilaa jännitteisemmän. Aineistossa esiintyneet teemat ovat luonnollisesti myös aikansa tuotteita. Jos aineisto olisi kerätty neljä vuotta aiemmin, ei kirjoituksissa viitattaisi Angry Birdsiin tai Mikael Granlundiin ja Suomen jääkiekkomaajoukkueen kevään 2011 maailmamestaruuteen. Niin ikään osa mediahahmoista jää päiväperhosiksi siinä missä toiset, kuten tässä tutkimuksessa Disney-perhe, ovat vakiinnuttaneet asemansa usean sukupolven kiintymyksen kohteena.

Aineiston rajaaminen vain teksteihin ei luonnollisesti valaise kohdettaan samassa laajuudessa kuin esimerkiksi Anne Haas Dysonin (2003; 2010) etnografiset tutkimukset. Pelkkien tekstienkin analysoinnin perusteella kolmas tila muodostui hybridimäiseksi tilaksi, jossa sosiaaliset suhteet ja mediaviitteet ovat tiiviissä yhteydessä toisiinsa. Lapset liittivät usein ystävänsä osaksi kirjoitusten henkilökavalkadia, mutta suhteisuus näkyi myös sukupuolittuneesti eriytyneissä mediakulttuuriin viittaavissa kirjoitusteemoissa. Mielenkiintoinen yksityiskohta oli se, että suhdetarjoumien muututtua hetkellisesti hiihtolomaviikon ajaksi, aineisto rikastui epätyypillisen kirjoittajaparin (tyttö-poika-pari) tuotoksella, joka oli yhdistelmä poikien seikkailu- ja kamppailukuvastoa sekä tyttöjen ihmissuhdeaineksia. Lisäksi kirjoituksissa esitetyt todellisuuskuvaukset erosivat reaalimaailman todellisuudesta. Mistä lapsi kertoo silloin, kun hän kirjoittaa tarinaa, jossa vanhempien ja lasten roolit sekoittuvat esimerkiksi niin, että ystävän äiti pyytää kirjoittajaa leikkimään? Kiintymyksestä, toiveista, perheiden leikkisästä toimintakulttuurista, omasta huumorintajustaan? Tähän pelkkä teksti ei kykene vastaamaan.

Vaikka artikkelini valaisee kotimaisessa kontekstissa paitsioon jäänyttä tutkimusaluetta, herättää se samalla lukuisia uusia kysymyksiä. Jo esitettyjen kysymysten lisäksi vakiintuneita sosiaalisia ryhmittymiä murtavien kirjoittajaryhmien toimintaa ja tuotoksia olisi tuloksissa läpikäydyn yksittäisen esimerkin valossa kiehtovaa tutkia tarkemmin. Myös tutkimusasetelmaa voisi syventää etnografisin metodein ja tutkimuskohdetta laajentaa koskemaan sekä tuotetuissa mediateksteissä että muussa sosiaalisessa kanssakäymisessä ilmenevää suhteisuutta ja näiden suhteiden välisiä relaatioita. Tämä asetelma huomioimalla olisi mahdollista saada lisää tietoa siitä, millainen merkitys ajallisesti lyhytkestoisilla, mutta laajasti ikäluokkaa innoittavilla mediakulttuuri-ilmiöillä on lasten keskinäisille suhteille pidemmällä ajanjaksolla ja millainen merkitys tässä prosessissa on lasten subjektiivisilla piirteillä, kuten taitavan piirtäjän kyvyllä tuottaa tarkkoja kopioita jaetun affektion kohteesta. Esimerkiksi bourdieulaisen käsitteistön avulla tällainen tutkimus tuottaisi arvokasta lisätietoa lasten omasta, mediasta ammentavasta, mutta persoonallisesta ja uniikista kulttuurista yhtenä lapsuuden kentän sosiaalisista pääomista.

\section{Viitteet}

1 Opettajien asenteita ja uskomuksia on toki tutkittu runsaasti, mutta ei kolmannen tilan muodostumisen viitekehyksestä.

2 Kahta Star Wars -episodia (IV ja VI), jotka ovat K-7, merkinnällä varustettuja, kyseiset elokuvat ovat vähintään K-11 -merkitty. 


\section{Kirjallisuus}

Blakemore, Judith \& Centers, Renee (2005). Characteristics of boys' and girls' toys. Sex Roles 53: 9-10, 619-633.

Downs, A. Chris (1983). Letters to Santa Claus: Elementary school-age children's sex typed toy preferences in a natural setting, Sex Roles 9: 2, 159-163.

Dredger, Katie; Woods, Daniel; Beach, Crystal \& Sagstetter, Victoria (2010). Engage me: Using new literacies to create third space classrooms that engage studen writers. Journal of Media Literacy Education 2: 2, 85-101.

Elbaz-Luwsisch, Freema; Moen, Torill \& Gudmunsdottir, Sigrun (2002). The multivoicedness of classroom. Bakhtin and narratives of teaching. Teoksessa: Huttunen, Rauno; Heikkinen, Hannu L.T. \& Syrjälä, Leena (toim.). Narrative Research: Voices of Teachers and Philosophers. Jyväskylä: Sophi, 197-217.

Evans, Janet (2002). The true story of Insy Winsy by A. Spider. Reading Literacy and Language 36: 2, 88-94.

Gerde, Hope K; Bingham, Gary E. \& Wasik, Barbara A. (2012). Writing in early childhood classrooms: Guidance for best practices. Early Childhood Education Journal 40: 6, 351-359.

Graham, Lynda (2001). From Tyrannosaurus to Pokemon: Autonomy in the teaching of writing. Reading 35 : $1,18-26$.

Haas Dyson, Anne (2003). "Welcome to the Jam": Popular culture, school literacy, and the making of childhoods. Harvard Educational Review 73: 3, 328-361.

Haas Dyson, Anne (2010). Writing childhoods under construction: Re-visioning `copying 'in early childhood. Journal of Early Childhood Literacy 10: 7, 7-31.

Hall, Stuart (2005). Identiteetti. Tampere: Vastapaino.

Heiskanen, Jukka (2007). Aku Ankka - Suomalainen instituutio. Teoksessa: Pentikäinen, Leena; Ruhala, Anu \& Niinistö, Hanna (toim.). Mediametkaa! Osa 2. Kasvattajan matkaopas lasten mediamaailmaan. Jyväskylä: Gummerus Oy, 93-95.

Hesterman, Sarah (2011). Multiliterate Star Warians: The force of popular culture and ICT in early learning. Australasian Journal of Early Childhood 36: 4, 86-95.

Ivanic, Roz (2004). Discourses of writing and learning to write. Language and Education 1: 3, 220-245.

Jokinen, Päivi; Palmgren-Neuvonen, Laura; Hytönen, Marja; Cortés, Marta; Riekki, Jukka \& Korkeamäki, Riitta-Liisa (2013). Millaista on tulevaisuuden lukutaitojen pedagogiikka? Tutkimus- ja kehittämistyötä perusopetukseen valmistavassa opetuksessa. Kieli, koulutus ja yhteiskunta, Syyskuu 2013. Saatavilla : http://www.kieliverkosto.fi/journals/kieli-koulutus-ja-yhteiskunta-syyskuu-2013 (luettu 3.4.2014).

Kalliala, Marita (1999). Enkeliprinsessa ja itsari liukumäessä: Leikkikulttuuri ja yhteiskunnan muutos. Helsinki: University Press Finland Ltd.

Karimäki, Reeli (2007). Media leikkiin innoittajana. Teoksessa: Pentikäinen, Leena; Ruhala, Anu \& Niinistö, Hanna (toim.). Mediametkaa! Osa 2. Kasvattajan matkaopas lasten mediamaailmaan. Jyväskylä: Gummerus Oy, 40-47.

Kellner, Douglas \& Share, Jeff (2005). Toward critical media literacy: Core concepts, debates, organizations, and policy. Discourse: Studies in the Cultural Politics of Education 26: 3, 369-386.

Korkeamäki, Riitta-Liisa (1996). How First Graders and Kindergarten Children Constructed Literacy Knowledge in the Context of Story Reading and Meaningful Writing. Acta Universitatis Ouluensis. Scientiae Rerum Socialium 21. Oulu: Oulu University Press.

Korkeamäki, Riitta-Liisa (2011a). New literacies: Millaista on oppia lukemaan ja kirjoittamaan 200o-luvulla? Teoksessa: Mikkola, Henna; Jokinen, Päivi \& Hytönen, Marja (toim.). Tulevaisuuden koulua kehittämässä. Uusi teknologia haastaa ja inspiroi. Oulu: Uniprint Oy, 13-18.

Korkeamäki Riitta-Liisa (2011b). Kieli ja vuorovaikutus oppimisympäristöissä. Teoksessa: Nurmilaakso, Marja \& Välimäki, Anna-Leena (toim.). Lapsi ja kieli. Kielellinen kehittyminen varhaiskasvatuksessa. Helsinki: Unigrafia Oy, 43-52.

Kupiainen, Reijo (2007a). Pienten lasten medialukutaito. Teoksessa: Pentikäinen, Leena; Ruhala, Anu \& Niinistö, Hanna (toim.). Mediametkaa! Osa 2. Kasvattajan matkaopas lasten mediamaailmaan. Jyväskylä: Gummerus Oy, 15-22.

Kupiainen, Reijo (2007b). Collaborative literacy and media education. Konferenssiesitelmä Pohjoismaisessa Mediakasvatus.nyt -mediakasvastuskonferenssissa Vaasassa 10.-11.5.2007.

Laukka, Maria (2004). Leikkikalujen elämästä. Teoksessa: Piironen, Liisa (toim.). Leikin Pikkujättiläinen. Porvoo: WS Bookwell Oy, 386-395. 
Levy, Rachael (2008). 'Third spaces' are interesting places: Applying 'third space theory 'to nursery-aged children's constructions of themselves as readers. Journal of Early Childhood Literacy 8: 1, 43-66.

Lindahl, Mats G. \& Folkesson, Anne-Mari (2012). Can we let computers change practice? Educators' interpretations of preschool tradition. Computers in Human Behavior 28: 5, 1728-1737

Makkonen, Heli (2005). Yhteistoiminnallisuus tavoitteena ja voimavarana: Esiopetusikäisten lasten vertaistyöskentely avoimessa tehtävässä tietokoneella. Joensuun yliopiston kasvatustieteellisiä julkaisuja $\mathrm{N}: 0$ 103. Joensuu: Joensuun Yliopistopaino.

Marsh, Jackie (2006). Popular culture in the literacy curriclum: A Bourdieuan analysis. Reading Research Quarterly 41: 2, 160-174.

Mediakasvatus kuntien varhaiskasvatuksessa (2013).Opetus- ja kulttuuriministeriön julkaisuja 2013:10. Saatavilla : http://www.minedu.fi/export/sites/default/OPM/Julkaisut/2013/liitteet/okm10.pdf?lang=fi (luettu 28.2.2014).

Mertala, Pekka; Karikoski, Hannele; Tähtinen, Liisa \& Sarenius, Vesa-Matti (2014). The Value of Toys. Konferenssiesitelmä Lapsuudentutkimuksen päivillä Oulussa 9.5.2014.

Moje, Elizabeth; McInthos Ciechanowski, Kathryn; Kramer, Katherine; Ellis, Lindsay; Carrillo, Rosario \& Collazo, Tehani (2004). Working toward third space in content area literacy: An examination of everyday funds of knowledge and discourse. Reading Research Quarterly. 39: 1, 38-70.

Niinistö, Hanna \& Ruhala, Anu (2007). Pienten lasten mediakasvatus. Teoksessa: Kynäslahti, Heikki; Kupiainen, Reijo \& Lehtonen, Miika (toim.). Näkökulmia mediakasvatukseen. Mediakasvatusseuran julkaisuja 1:2007. Saatavilla: http://www.mediakasvatus.fi/publications/ISBN978-952-99964-1-4.pdf (luettu 28.2.2014), 123-136.

Niinistö, Hanna \& Sintonen, Sara (2007). Mä keksin! Tehdään yhdessä mediakulttuuria. Teoksessa: Pentikäinen, Leena Ruhala, Anu \& Niinistö, Hanna (toim.). Mediametkaa! Osa 2: Kasvattajan matkaopas lasten mediamaailmaan. Jyväskylä: Gummerus Oy, 23-30.

Opetushallitus (2010). Esiopetuksen opetussuunnitelman perusteet. Opetushallitus määräykset ja ohjeet 210: 27. Tampere: Juvenes Print - Tampereen yliopistopaino.

Opetushallitus (2014a). Esiopetuksen opetussuunnitelman perusteet 2014. Saatavilla: http://www.oph.fi/ download/163781_esiopetuksen_opetussuunnitelman_perusteet_2014.pdf (luettu 21.1.2014).

Opetushallitus (2014b). Perusopetuksen opetussuunnitelman perusteet 2014. Saatavilla: http://www.oph.fi/ download/163777_perusopetuksen_opetussuunnitelman_perusteet_2014.pdf (luettu 21.1.2014).

Pahl, Kate \& Kelly, Sally. (2005). Family literacy as third space between home and school: some case studies of practice. Literacy 39: 2, 91-96.

Pahl, Kate \& Rowsell, Jennifer (2005). Literacy and Education. Understanding New Literacy Studies in the Classroom. London: Sage Publications.

Palmgren-Neuvonen, Laura; Mikkola, Henna \& Kumpulainen, Kari (2011). FutureStory: Digitarinat yhteistoiminnallisen oppimisen edistäjänä. Teoksessa: Mikkola, Henna; Jokinen, Päivi \& Hytönen, Marja (toim.). Tulevaisuuden koulua kehittämässä: Uusi teknologia haastaa ja inspiroi. Oulu: Uniprint Oy, 73-92.

Pekkala, Leo; Pääjärvi, Saara; Palsa, Lauri; Korva, Saana \& Löfgren, Anu. (2013). Katsaus suomalaisen mediakasvatustutkimuksen kenttään. Selvitys kotimaisesta mediakasvatukseen liittyvästä tutkimuksesta erityisesti opinnäytteiden ja journaaliartikkeleiden osalta pääosin vuosien 2007-2012 ajalta. Saatavilla: http://www.meku.fi/kirjallisuuskatsaus.pdf (luettu 13.9.2014).

Pääjärvi, Saara \& Sommers-Piiroinen, Johanna (2013). Mediakasvatus kuuluu kuvaan varhaiskasvatuksessa: Kokemusten jakamista ja toimintamalleja varhaisen mediakasvatuksen yhteiseen kehittämiseen. Mediakasvatus- ja kuvaohjelmakeskus MEKU. Saatavilla: http://www.mediataitokoulu.fi/kuuluukuvaan. pdf (luettu 16.1.2015).

Rantala, Leena (2011). Finnish Media Literacy Education Policies and Best Practices in Early Childhood Education and Care Since 2004. Journal of Media Literacy Education 3: 2, 123-133.

Rintakorpi, Kati. (2007). Mediamatkalla ilmaisupäiväkoti Illuusiassa. Teoksessa: Pentikäinen, Leena; Ruhala, Anu \& Niinistö, Hanna (toim.). Mediametkaa! Osa 2. Kasvattajan matkaopas lasten mediamaailmaan. Jyväskylä: Gummerus Oy, 106-115.

Siljander, P (1988). Hermeneuttisen pedagogiikan pääsuuntaukset. Oulu: Oulun yliopisto

Suoranta, Juha. (2003). Kasvatus mediakulttuurissa. Jyväskylä: Gummerus kirjapaino Oy.

Suoninen, Annikka (2008). Mediakasvatus päiväkodissa ja esiopetuksessa: Mediakasvatuksen tilan ja Mediamuffinssi-oppimateriaalien käyttöönoton arviointi syksyllä 2007. Jyväskylän yliopisto. Nykykulttuurin tutkimuskeskus. Saatavilla: https://staff.jyu.fi/Members/kuilju/mediakasvatus_paivakodissa_raportti. pdf (luettu 16.1.2015). 
Suoninen, Annikka (2014). Lasten mediabarometri 2013: o-8 -vuotiaiden mediankäyttö ja sen muutokset vuodesta 2010. Nuorisotutkimusverkosto / Nuorisotutkimusseura verkkojulkaisuja 75 . Saatavilla: http://www.nuorisotutkimusseura.fi/julkaisuja/lastenmediabarometri2013.pdf (luettu 5.4.2014).

Suvilehto, Pirjo (2008). Lasten luova kirjoittaminen psyykkisen tulpan avaajana: Tapaustutkimus pohjoissuomalaisen sairaalakoulun ja Päätalo-Instituutin 8-13-vuotiaiden lasten kirjoituksista. Acta Universitatis Ouluensis. Humaniora 83. Oulu: Oulu University Press.

Trageton, Arne (2007). Lukemaan oppiminen kirjoittamalla. Juva: WS Bookwell Oy.

Uusikylä, Kari (2002). Rohkeus ja välittäminen. Teoksessa: Etiikka koulun arjessa. Keuruu: OAJ ja Otava, 9-21.

Vasquez, Vivian (2004). Resistance, power-tricky and colorless energy: What engagement with everyday popular culture texts can teach us about learning and literacy. Teoksessa: Marsh, Jackie (toim.). Popular Culture, New Media and Digital Literacy in Early Childhood. London: Routledge, 201-218.

Vera, Debbie (2011). Using popular culture print to increase emergent literacy skills in one high-poverty urban school district. Journal of Early Childhood Literacy, 11: 3, 307-330.

Viljamaa, Elina (2012). Lasten tiedon äärellä: Äidin ja lasten kerronnallisia kohtaamisia kotona. Acta Universitatis Ouluensis. Scientiae Rerum Socialium 129. Tampere: Juvenes Print.

Vuorisalo, Mari (2013). Lasten kentät ja pääomat. Osallistumisen ja eriarvoisuuksien rakentuminen päiväkodissa. Jyväskylä studies in education, psychology and social research 467. Jyväskylä: Jyväskylä Unversity Printing House.

Wilson, Anita (2000). There's no escape from the third-space theory: borderland discourse and 'in-between' literacies of prisons. Teoksessa: Barton, D; Hamilton, Mary \& Ivanic, Roz (toim.). Situated Literacies. Reading and Writing in Context. London: Routledge. 45-69. 